\title{
Middle-aged female with palpable swelling over the abdominal wall
}

\author{
Amar Udare $^{1} \cdot$ Sanjay Desai ${ }^{1} \cdot$ Aruna Chandorkar $^{2} \cdot$ Sujit Joshi $^{2}$
}

Published online: 18 December 2017

(C) ISS 2017

A 31-year-old female presented with a palpable swelling for 3 years over the left lower abdominal wall with recent increase in size. Figure 1 (axial T1W), Fig. 2 (axial T2 fat-saturated), Fig. 3 (DWI and ADC) and Fig. 4 (early arterial and venous phase post contrast T1 fat-saturated) MR images were acquired. Postbiopsy photomicrographs are also provided (Figs. 5 and 6).

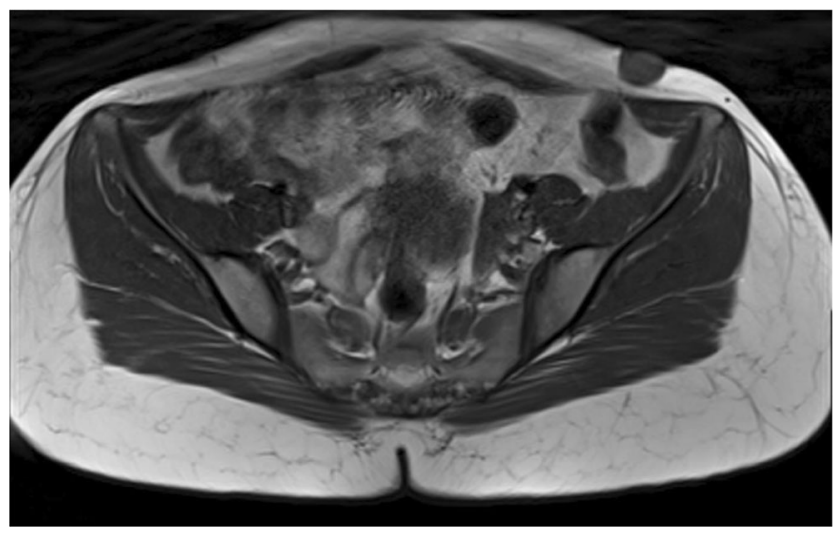

Fig. 1 Axial T1

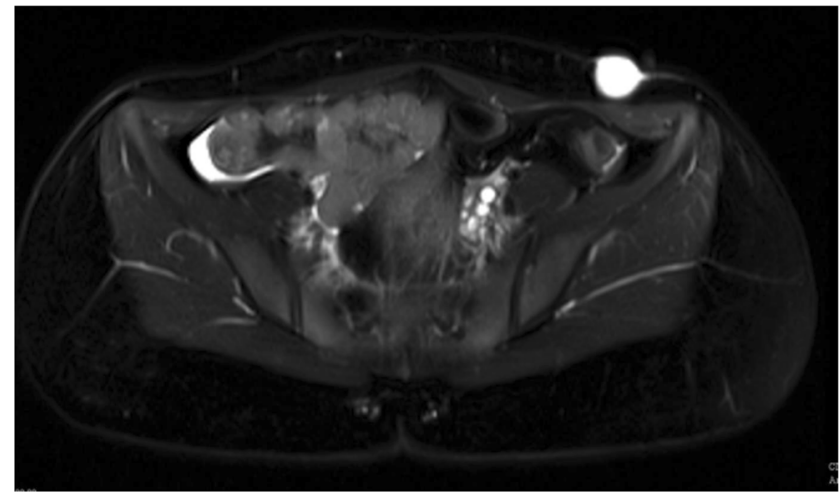

Fig. 2 Axial T2 FS

The diagnosis can be found at https://doi.org/10.1007/s00256-017-2849-5

Amar Udare

amarudare@gmail.com

1 Department of Radiology, Deenanath Mangeshkar Hospital and Research Centre, Pune, India

2 Department of Pathology, Deenanath Mangeshkar Hospital and Research Centre, Pune, India 


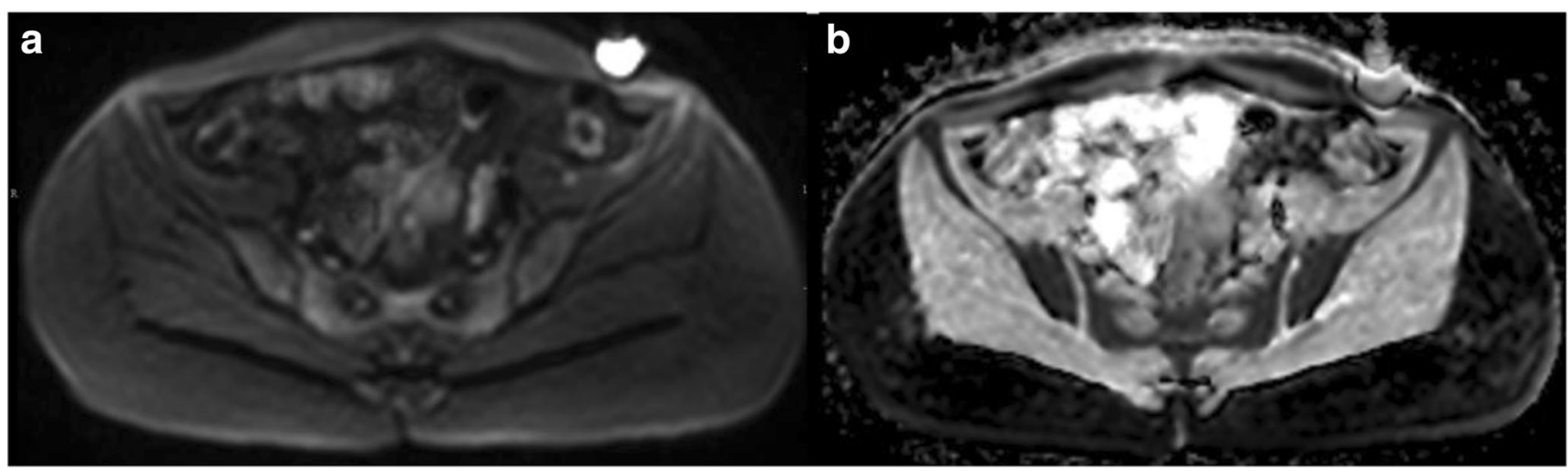

Fig. 3 a-b DWI image and ADC images

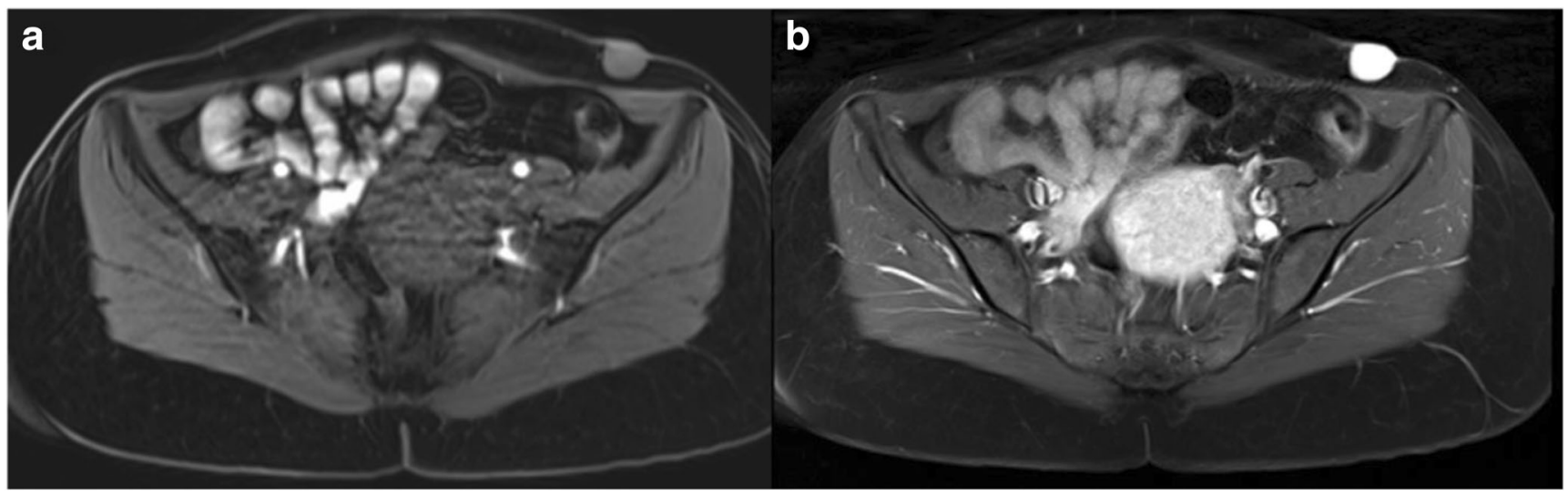

Fig. 4 a-b Post-contrast T1 FS images in early arterial and venous phase

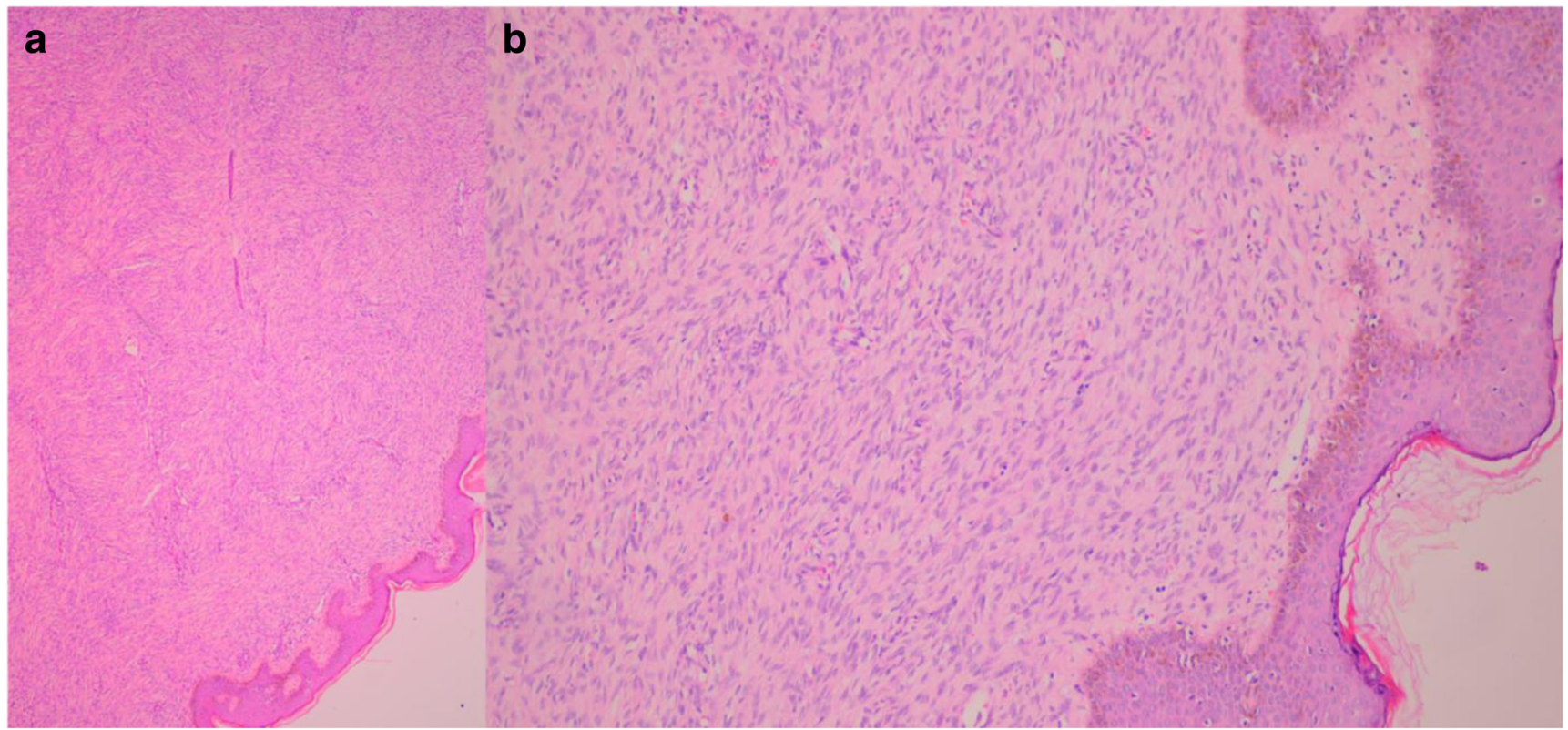

Fig. 5 a-b H \& E stain photomicrographs at $4 \times$ and $20 \times$ magnification respectively 


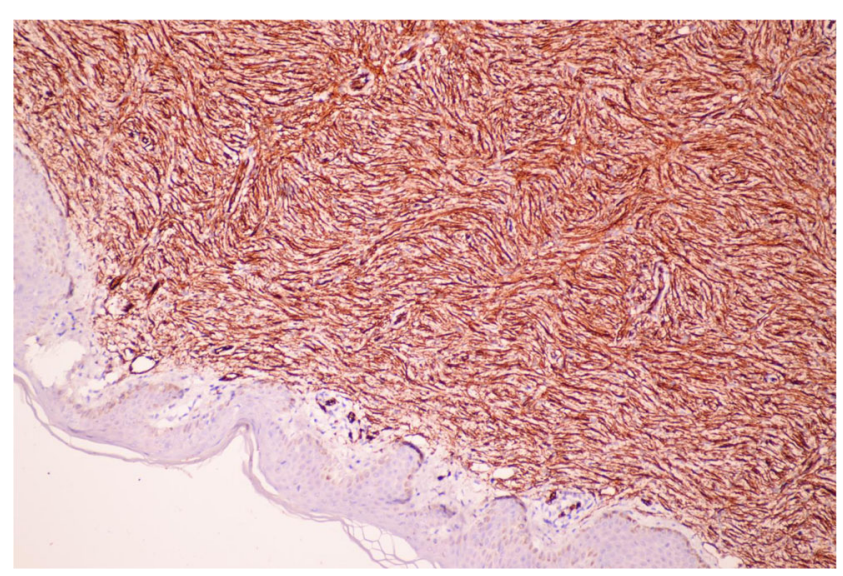

Compliance with ethical standards

Grants received None.

Disclosures None.

Conflict of interest None.

Fig. 6 Photomicrograph of IHC for CD34 